\title{
DTM GENERATION WITH UAV BASED PHOTOGRAMMETRIC POINT CLOUD
}

\author{
N. Polat ${ }^{\mathrm{a}, *}$, M. Uysal ${ }^{\mathrm{a}}$ \\ ${ }^{a}$ AKU, Engineering Faculty, Gazlıgol yolu Afyonkarahisar, Turkey - (npolat,muysal)@aku.edu.tr
}

KEY WORDS: UAV, point cloud, DTM

\begin{abstract}
:
Nowadays Unmanned Aerial Vehicles (UAVs) are widely used in many applications for different purposes. Their benefits however are not entirely detected due to the integration capabilities of other equipment such as; digital camera, GPS, or laser scanner. The main scope of this paper is evaluating performance of cameras integrated UAV for geomatic applications by the way of Digital Terrain Model (DTM) generation in a small area. In this purpose, 7 ground control points are surveyed with RTK and 420 photographs are captured. Over 30 million georeferenced points were used in DTM generation process. Accuracy of the DTM was evaluated with 5 check points. The root mean square error is calculated as $17.1 \mathrm{~cm}$ for an altitude of $100 \mathrm{~m}$. Besides, a LiDAR derived DTM is used as reference in order to calculate correlation. The UAV based DTM has o $94.5 \%$ correlation with reference DTM. Outcomes of the study show that it is possible to use the UAV Photogrammetry data as map producing, surveying, and some other engineering applications with the advantages of low-cost, time conservation, and minimum field work.
\end{abstract}

\section{INTRODUCTION}

The Digital Terrain Model (DTM) is an important topographic product and essential demand for many applications. Traditional methods for creating DTM are very costly and time consuming because of land surveying. In time, Photogrammetry has become one of the major methods to generate DTM. Recently, airborne Light Detection and Ranging (LiDAR) system has become a powerful way to produce a DTM due to advantage of collecting three-dimensional information very effectively over a large area by means of precision and time (Polat and Uysal, 2015). However, the main disadvantage of aerial manned platforms such as airplanes is being expensive, especially for small study areas. During the last decades, low-cost Unmanned Aerial Vehicles (UAVs) are used to pass this handicap. Nowadays, the use of UAVs is increasing day by day due to its advantages at cost, inspection, surveillance, reconnaissance, and mapping (Remondino et.al., 2011).

DTM is a structured surface that contains elevation data with some critical features of terrain such as ridge lines, peak points etc. (Podopnikar et. Al., 2005). During the DTM generating process, higher vegetation-horizons, buildings and also other, non-terrain objects are removed (Lohman and Koach, 1999). Removing non-terrain objects to get bare earth is called filtering. The ground filtering is an essential step to separate points which are from the ground surface and which are from non-ground features for almost all topographic applications. Distinguishing ground from non-ground can be a considerable challenge in regions with high surface variability (Vosselman, 2000; Axelsson, 2000). Besides accurate DTMs can only be generated if non-ground points are removed successfully (Shan and Sampth, 2005). In this study the generation of DTM with UAV based photogrammetric point cloud and its accuracy analysis is presented.

\section{STUDY AREA AND DATA}

The study area is located in Izmir-Bergama (2.06 km2) (Figure 1). A Lidar derived DTM is used as reference data. Besides, five checkpoints are used in the calculation of root mean square error. 420 UAV based images are captured. The average ground sample distance is $7.59 \mathrm{~cm}$. 7 Ground Control Points (GCP) were measured before the flight in purpose of geo referencing.

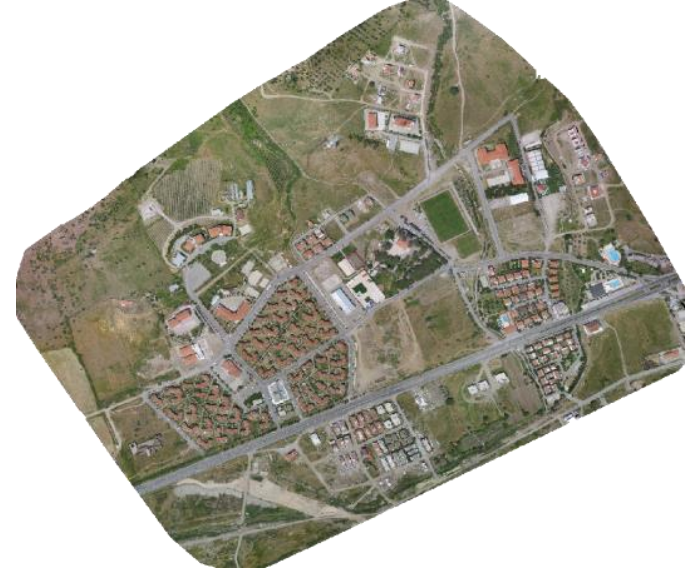

Figure 1. study area, Izmir-Bergama

\section{METHODOLOGY}

\subsection{Image processing}

The main aim of process is to produce a georeferenced 3D point cloud by handling with overlapping aerial image data (Siebert and Teizer, 2014). The approach of point cloud generation from images is called as Structure from Motion (SfM). SfM runs under the same basic conditions as stereoscopic Photogrammetry. It uses overlapping images in order to get a $3 \mathrm{~d}$ structure of interested object. Existing software's can generate a 3D point cloud such as; Agisoft PhotoScan (commercial software) that has been used in this study. The software advances in UAV applications and allows generating orthophoto in a willed coordinate system. For a full performance of software, it's recommended to use a powerful computer due to the huge amount of data (Siebert and Teizer, 
2014). The data processing is relatively easy. It starts with uploading photos from camera to computer and eliminating distorted or blurred ones. We used 420 selected images. The GCPs were used for geo referencing. At the end of image processing 30461747 georeferenced points are obtained with a density of 8.76 (points/m2) (Figure 2).

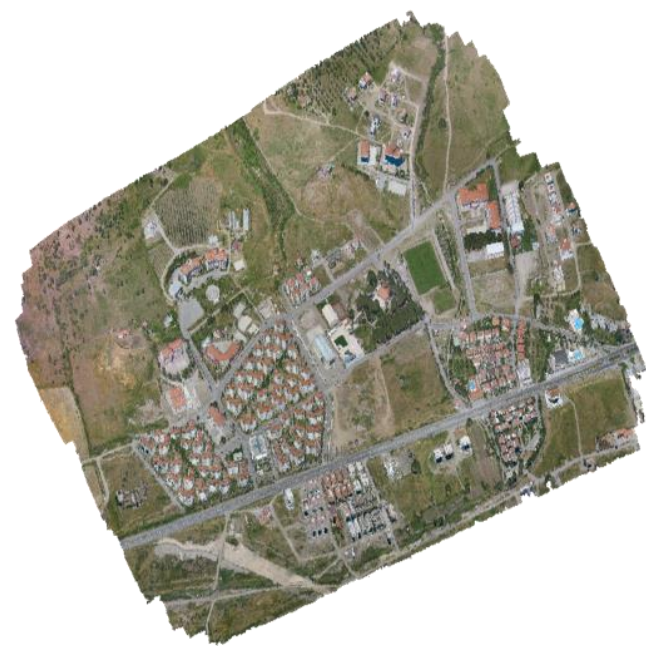

Figure 2. Image based point cloud (30461747)

\subsection{Cloth Simulation Filtering (CSF)}

The CSF algorithm is designed for the producing of DTM from LiDAR point cloud (Zhang et al., 2016). It is assumed that a soft enough cloth sticks to the surface and refers to digital surface model. But, if the surface is turned upside down, the final shape of the cloth defines a digital terrain model (Figure $3)$.

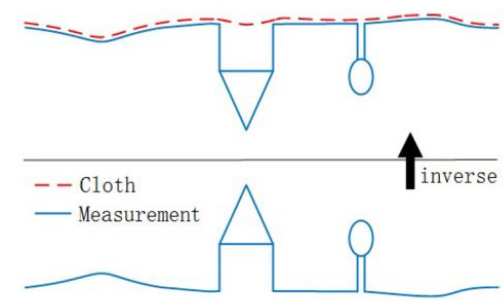

Figure 3. Overview of the cloth simulation algorithm (Zhang et

al. 2016)

At the end of filtering process, 26138351 points are detected as ground point (Figure 4). The obtained ground points are used to generate a $0.5 \mathrm{~m}$ resolution DTM

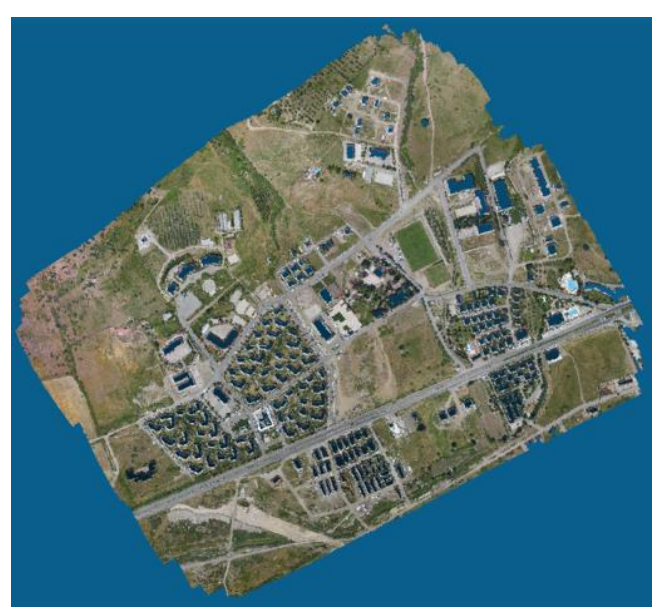

Figure 4. RGB encoded ground points of study area

\section{ANALAYSIS}

In order to get root mean square error (RMSE) of Z, five new check points are used with the following equation (1).

$$
\mathrm{RMSE}=\sqrt{\frac{(z \text { dem }-Z \mathrm{ref})^{2}}{n}}
$$

Where Zdem is the elevation value from the generated DTM, and Zref is the correspondent reference elevation value from check points. $\mathrm{n}$ is the number of check points. The calculated RMSE is $0.171 \mathrm{~m}$. The reference DTM is obtained from Lidar data presented by Kay1 et al. (2016).

The correlation coefficient is a measure that refers the statistical correlation between the UAV based DTM values and the values of reference. Calculated coefficients indicate the goodness of fit of surfaces. The image based calculated correlation coefficient is 0.945 . The reference and UAV based DTM are at the figure 5 and figure 6.

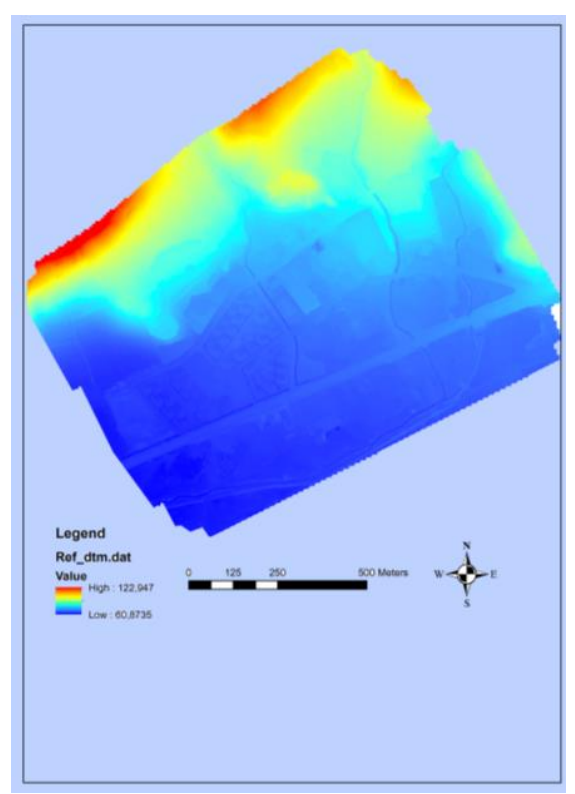

Figure 5. The reference DTM 


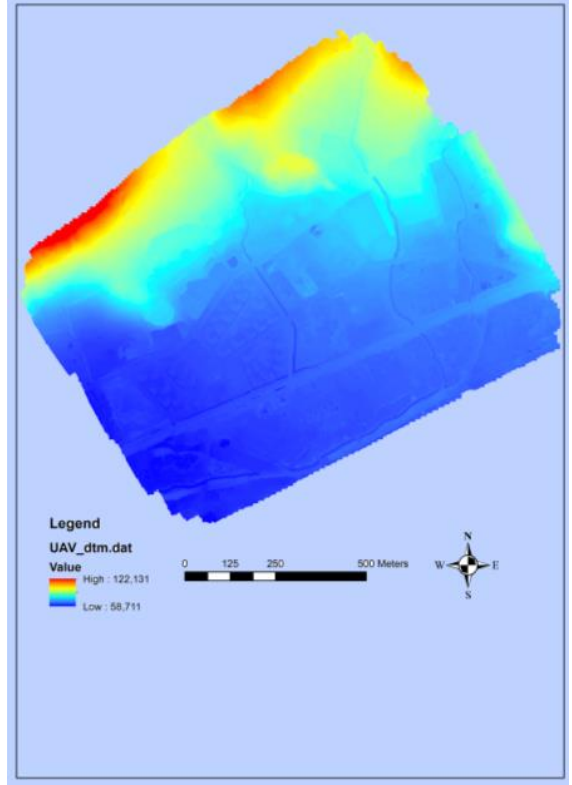

Figure 6. The UAV based DTM

\section{CONCLUSION}

This paper indicates the capability of UAVs, which is an alternative data collection technology, in a geomatic application in a small area by means of DTM generation with. Comparing with traditional manned airborne platforms, they reduce the working costs and minimize the danger of reaching to risky study sites, with sufficient accuracy. In fact, the UAV systems have lots of advantages (low-cost, real time, high temporal and spatial resolution data, etc.) which are very important for not only geomatic but also various disciplines. The application indicates that the UAV combined digital camera systems can allow to collect usable data for geomatic applications. The study shows that UAV based data can be used for DTM generation by photogrammetric techniques with a vertical accuracy of 17.1 $\mathrm{cm}$. It can be stated that the UAV Photogrammetry can be used in engineering applications with the advantages of low-cost, time conservation, minimum field work, and competence accuracy. Moreover the created 3D model is satisfactory to realize topography with texture. On the other hand, except GCP some parameters such as weather, vibrations, lens distortions, and software directly affects the process and model accuracy. Beyond all these, the UAVs system is not fully automated and still needs a user decision. Future studies may offer an automated approach for UAVs that minimizes the user attraction.

\section{ACKNOWLEDGEMENTS}

This study is supported by Afyon Kocatepe University, project numbered 16.FEN.BIL.18.

\section{REFERENCES}

Axelsson, P., 2000. DEM generation from laser scanner data using adaptive TIN models. Int. Arch. Photogramm. Remote Sen. $110-117$

Kayı, A., Erdogan, M., Eker, O., 2015. OPTECH HA-500 ve RIEGL LMS-Q1560 ile Gerçekleştirilen LIDAR Test Sonuçları. Harita Dergisi Ocak 2015 Sayı 153 (in Turkish)
Lohmann, P., Koch, A. 1999. ISPRS Workshop on Sensing and Mapping from Space "Quality assessment of laser-scannerdata."University of Hanover, Germany.

Podobnikar, T., Stancic, Z., K. Oštir, 2000. ISPRS WG VI/3 and IV/3 meeting "Data integration for the DTM Production.”Ljubljana.

Polat, N., M. Uysal, 2015. Investigating performance of airborne lidar data filtering algorithms for DTM generation. Measurement,61-68.

Remondino, F., Barazzetti, L., Nex, F. M. Scaioni, D. Sarazzi, 2011. ISPRS ICWG I/V UAV-g Conference "UAV Photogrammetry for mapping and 3D modeling current status and future perspectives" Zurich, Switzerland.

Shan, J., Sampath, A., 2005. Urban DEM generation from raw LiDAR data: a labeling algorithm and its performance, Photogramm. Eng. Remote Sens. 217-226.

Siebert, S. Teizer, J. 2014. Mobile 3D mapping for surveying earthwork projects using an Unmanned Aerial Vehicle (UAV) system. Autom Constr. 1-14.

Vosselmann, G. 2000. Slope based filtering of Laser altimetry data. Int. Arch. Photogramm. Remote Sens. 935-942.

Zhang, W., Qi, J., Wan, P., Wang, H., Xie, D., Wang, X., and Yan, G. 2016. An easy-to-use airborne lidar data filtering method based on cloth simulation. Remote Sensing, 8(6). 